\title{
Erysipelas in an atypical location
}

\section{Róża w nietypowej lokalizacji}

Beata Wańczyk-Dręczewska, Agnieszka B. Owczarczyk-Saczonek, Waldemar J. Placek

Department of Dermatology, Sexually Transmitted Diseases and Clinical Immunology, The University of Warmia and Mazury, Olsztyn, Poland

Klinika Dermatologii, Chorób Przenoszonych Drogą Płciową i Immunologii Klinicznej, Uniwersytet Warmińsko-Mazurski w Olsztynie, Polska

\section{CORRESPONDING AUTHOR/} ADRES DO KORESPONDENCJI:

Beata Wańczyk-Dręczewska

Klinika Dermatologii,

Chorób Przenoszonych

Drogą Płciową

i Immunologii Klinicznej

al. Wojska Polskiego 30

10-229 Olsztyn

e-mail: beata.wanczyk@gumed.edu.pl

\begin{abstract}
Erysipelas is an acute bacterial disease of the skin and subcutaneous tissue. Its most commonly caused by group A beta-haemolytic Streptococci. Factors predisposing to infection include: old age, chronic diseases and immunodeficiency. Erysipelas the most typically develops on lower limbs. Very rarely the lesions are located on the trunk or the genital area. The clinical course is characteristic and includes: sudden onset, high fever, chills, pain as well as swelling, redness and excessive heat of the skin. The article describes a case of a female patient with erysipelas located in the back with a history of chronic myeloid leukaemia. In the differential diagnosis, skin lesions in the course of leukaemia and carcinomatous erysipelas had to be taken into account. The atypical location of skin lesions may have been caused by impairment and dysregulation of the immune system, both secondary to leukaemia and the use of an immunosuppressive drug. In dermatological practice, less typical locations of the infection have to be considered. Early implementation of appropriate treatment allows achievement of therapeutic success and avoiding complications.
\end{abstract}

\section{STRESZCZENIE}

Róża jest ostrą chorobą bakteryjną skóry i tkanki podskórnej. Czynnikiem etiologicznym są najczęściej paciorkowce $\beta$-hemolizujące grupy A. Wśród czynników predysponujących do zakażenia należy wymienić: podeszły wiek, choroby przewlekłe oraz niedobory odporności. Najbardziej typową lokalizacją róży są kończyny dolne. Bardzo rzadko zmiany umiejscowione są na tułowiu lub w okolicy narządów płciowych. Przebieg kliniczny jest charakterystyczny i obejmuje: nagły początek, wysoką temperaturę, dreszcze, dolegliwości bólowe oraz obrzęk, zaczerwienienie i nadmierne ucieplenie skóry. W artykule opisano przypadek pacjentki z różą zlokalizowaną w obrębie pleców $\mathrm{z}$ wywiadem przewlekłej białaczki szpikowej. $\mathrm{W}$ rozpoznaniu różnicowym należało wziąć pod uwagę zmiany skórne w przebiegu białaczki oraz różę nowotworową. Niecharakterystyczne umiejscowienie zmian skórnych mogło być spowodowane upośledzeniem i dysregulacją układu odpornościowego po przebytej białaczce, a także stosowaniem leku immunosupresyjnego. W praktyce dermatologicznej należy pamiętać o mniej typowych lokalizacjach tego zakażenia. Wczesne wdrożenie 
odpowiedniego leczenia pozwala osiągnąć sukces terapeutyczny oraz uniknąć powikłań.

Key words: erysipelas, leukaemia, chronic meyloid leukaemia, bacterial diseases.

Słowa kluczowe: róża, białaczka, przewlekła białaczka szpikowa, choroby bakteryjne.

\section{INTRODUCTION}

Erysipelas is an acute, contagious bacterial disease of the skin and subcutaneous tissue. It is most often caused by $\beta$-haemolytic Streptococci of group A, less often groups B, C, G and D, and also by Staphylococcus aureus or mixed bacterial strains [1]. Factors predisposing to infection include: old age, chronic diseases - mainly diabetes and atherosclerosis, chronic venous insufficiency, obesity, congenital and acquired immunodeficiencies and hygienic negligence $[2,3]$. Most typically erysipelas develops is in lower limbs (70-80\%), followed by the face and upper limbs [4]. Very rarely lesions are located on the trunk or the genital area (0.5-2.1\%) [4]. The clinical course is characteristic and includes: sudden onset, high fever of as much as $41^{\circ} \mathrm{C}$, chills, pain as well as swelling, redness and excessive heat of the skin. Skin lesions, very clearly demarcated from the non-affected tissues, have an irregular shape, the skin is smooth, taut and shiny. The differential diagnosis should primarily take into account: venous thrombosis, insect bites and stings, cellulitis, allergic contact dermatitis, drug reaction, animal erysipelas, herpes simplex infection, necrotizing fasciitis, as well as paraneoplastic syndrome - carcinomatous erysipelas [3,5] (table 1).

\section{OBJECTIVE}

The case study of a female patient with erysipelas located on the back.

\section{CASE REPORT}

A 46-year-old woman was admitted to the Department of Dermatology because of a erysipelas covering the entire surface of her back. First symptoms in the form of a fever of over $38^{\circ} \mathrm{C}$ appeared a week before the admission - she was taking azithromycin $500 \mathrm{mg}$ for 3 days, then she was referred to the Emergency Department due to the appearance of skin lesions on her back. At that time, she was treated as for allergic urticaria, with: clemastine, dexamethasone and hydroxyzine, without improvement. The pa-

\section{WPROWADZENIE}

Róża jest ostrą, zakaźną chorobą bakteryjną skóry i tkanki podskórnej. Czynnikiem etiologicznym są najczęściej paciorkowce $\beta$-hemolizujące grupy $\mathrm{A}$, rzadziej grup B, C, G oraz D, a także Staphylococcus aureus lub mieszane szczepy bakterii [1]. Wśród czynników predysponujących do zakażenia należy wymienić: podeszły wiek, choroby przewlekłe - głównie cukrzycę i miażdżycę, przewlekłą niewydolność żylną, otyłość, wrodzone i nabyte niedobory odporności oraz zaniedbania higieniczne $[2,3]$. Najbardziej typową lokalizacją róży są kończyny dolne (70-80\%), następnie twarz i kończyny górne [4]. Bardzo rzadko zmiany umiejscowione są na tułowiu lub w okolicy narządów płciowych (0,5-2,1\%) [4]. Przebieg kliniczny jest charakterystyczny i obejmuje: nagły początek, wysoką temperaturę, sięgającą $41^{\circ} \mathrm{C}$, dreszcze, dolegliwości bólowe oraz obrzęk, zaczerwienienie i nadmierne ucieplenie skóry. Zmiany skórne są bardzo wyraźnie odgraniczone od tkanek nieobjętych procesem chorobowym, mają nieregularny kształt, skóra jest gładka, napięta i lśniąca. W rozpoznaniu różnicowym pod uwagę należy wziąć przede wszystkim: zakrzepicę żylną, ukąszenia i użądlenia owadów, cellulitis, alergiczne kontaktowe zapalenie skóry, odczyn polekowy, różycę, zakażenie Herpes simplex, martwicze zapalenie powięzi, a także zespół paraneoplastyczny - różę nowotworową [3, 5] (tab. 1).

\section{CEL PRACY}

Opis przypadku pacjentki z różą zlokalizowaną w obrębie pleców.

\section{OPIS PRZYPADKU}

Kobieta 46-letnia została przyjęta do Kliniki Dermatologii z powodu róży obejmującej całą powierzchnię skóry pleców. Pierwsze objawy w postaci podwyższonej temperatury ciała powyżej $38^{\circ} \mathrm{C}$ pojawiły się tydzień przed przyjęciem - pacjentka przyjmowała azytromycynę w dawce $500 \mathrm{mg}$ przez 3 dni, następnie została skierowana do szpitalnego 
Table I. The differential diagnosis

Tabela I. Rozpoznanie różnicowe

\begin{tabular}{|c|c|}
\hline $\begin{array}{l}\text { Skin lesions/ } \\
\text { Zmiany } \\
\text { skórne }\end{array}$ & Symptoms/Objawy \\
\hline $\begin{array}{l}\text { Erysipelas/ } \\
\text { Róża }\end{array}$ & $\begin{array}{l}\text { Sudden onset, fever reaching } 41^{\circ} \mathrm{C} \text {, chills, pain, } \\
\text { swelling, redness and excessive heat of the skin. } \\
\text { Skin lesions of irregular shape, clearly demarcated } \\
\text { from the surrounding area; the skin is smooth, } \\
\text { taut and shiny/Nagły początek, gorączka sięgająca } \\
41^{\circ} \mathrm{C} \text {, dreszcze, dolegliwości bólowe oraz obrzęk, } \\
\text { zaczerwienienie i nadmierne ucieplenie w obrębie } \\
\text { skóry. Zmiany skórne o nieregularnym kształcie, } \\
\text { wyraźnie odgraniczone od otoczenia; skóra jest } \\
\text { gładka, napięta i lśniąca }\end{array}$ \\
\hline $\begin{array}{l}\text { Venous } \\
\text { thrombosis/ } \\
\text { Zakrzepica } \\
\text { żylna }\end{array}$ & $\begin{array}{l}\text { Pain, bruising, limb swelling; painful hardening of } \\
\text { the vein. Sub-febrile temperature/Ból, zasinienie, } \\
\text { obrzęk kończyny; bolesne stwardnienie żyły. Stan } \\
\text { podgorączkowy }\end{array}$ \\
\hline
\end{tabular}

\section{Aetiological factor or cause/ \\ Czynnik etiologiczny lub przyczyna}

Beta-haemolytic streptococci of group $A$, less common groups B, C, G and D, Staphylococcus aureus or mixed strains of bacteria/Paciorkowce

$\beta$-hemolizujące grupy A, rzadzie

grup B, C, G oraz D,

Staphylococcus aureus lub mieszane szczepy bakterii

Flow disorders and excessive blood coagulation/Zaburzenia przepływu i nadmierna krzepliwość krwi
Anti-thrombotic treatment, compressive therapy, surgical therapy/Leczenie przeciwkrzepliwe, kompresjoterapia, leczenie operacyjne

\begin{tabular}{lll}
\hline Cellulitis/ & Strong, vaguely demarcated erythema accompanied & Streptococcus pyogenes \\
Cellulitis & by pain and burning sensation. Skin lesions may be & + Staphylococcus aureus/ \\
& accompanied by fever and nausea/Silny, niewyraźnie & Streptococcus pyogenes + \\
& odgraniczony rumień z towarzyszącym bólem & Staphylococcus aureus \\
& i pieczeniem Z Zmianom skórnym może towarzyszyć &
\end{tabular}
i pieczeniem. Zmianom skórnym może towarzyszyć gorączka oraz nudności

Allergic contact Exudative papules and vesicles not clearly dermatitis/ demarcated from the surrounding; with severe Alergiczne itching, possible swelling and inflammation/ kontaktowe Grudki wysiękowe oraz pęcherzyki niewyraźnie zapalenie skóry odgraniczone od otoczenia; silny świąd, możliwe zmiany obrzękowe i zapalne

Drug reaction/ Various changes in the type of urticaria, oedema, Odczyn erythema, eczema/Różnorodne: zmiany typu polekowy pokrzywki, obrzęku, rumienia, wyprysku

Animal Sharply demarcated erythema, occupying dorsal erysipelas/ surfaces of fingers, passing to the back of the hand. Różyca Skin lesions are accompanied by minor itching and pain. No general symptoms/Ostro odgraniczony rumień zajmujący grzbietowe powierzchnie palców, przechodzący na grzbiet ręki. Zmianom skórnym towarzyszy niewielki świąd i ból. Brak objawów ogólnych

\begin{tabular}{|c|c|c|c|}
\hline $\begin{array}{l}\text { Herpes } \\
\text { simplex } \\
\text { infection/ } \\
\text { Zakażenie } \\
\text { Herpes simplex }\end{array}$ & $\begin{array}{l}\text { Sudden onset accompanied by fever. Diffuse } \\
\text { vesicular lesions with a tendency to cluster/ } \\
\text { Nagły początek z towarzyszącą gorączką. } \\
\text { Rozsiane zmiany pęcherzykowe z tendencją } \\
\text { do grupowania się }\end{array}$ & Herpes simplex/Herpes simplex & Acyclovir/Acyklowir \\
\hline $\begin{array}{l}\text { Necrotic } \\
\text { fasciitis/ } \\
\text { Martwicze } \\
\text { zapalenie } \\
\text { powięzi }\end{array}$ & $\begin{array}{l}\text { Violent course, symptoms of septic shock. Local } \\
\text { erythema accompanied by oedema. On that basis, } \\
\text { ulcerations and blisters develop, as well as necrosis/ } \\
\text { Gwaltowny przebieg, objawy wstrząsu septycznego. } \\
\text { Miejscowy rumień z towarzyszącym obrzękiem, } \\
\text { na którego podłożu rozwijają się owrzodzenia } \\
\text { i pęcherze, a także martwica }\end{array}$ & $\begin{array}{l}\text { Mixed bacterial flora/ Mieszana } \\
\text { flora bakteryjna }\end{array}$ & $\begin{array}{l}\text { Surgical treatment: } \\
\text { fasciotomy or amputation; } \\
\text { antibiotic therapy guided } \\
\text { by antibiogram/Leczenie } \\
\text { operacyjne: fasciotomia lub } \\
\text { amputacja; antybiotykoterapia } \\
\text { zgodnie z antybiogramem }\end{array}$ \\
\hline $\begin{array}{l}\text { Carcinomatous } \\
\text { erysipelas/ } \\
\text { Róża } \\
\text { nowotworowa }\end{array}$ & $\begin{array}{l}\text { Erythematous, tender, well-demarcated lesions } \\
\text { with a slightly raised edge. No general symptoms/ } \\
\text { Rumieniowe, tkliwe, dobrze odgraniczone zmiany } \\
\text { z nieznacznie uniesionym brzegiem. Brak objawów } \\
\text { ogólnych }\end{array}$ & $\begin{array}{l}\text { Cancer: most often breast cancer. } \\
\text { Also, thyroid, larynx, lung, ovary, } \\
\text { pancreatic and stomach cancer, } \\
\text { and melanoma/Nowotwory: } \\
\text { najczęściej piersi, a także tarczycy, } \\
\text { krtani, płuc, jajnika, trzustki } \\
\text { i żołądka oraz czerniak }\end{array}$ & $\begin{array}{l}\text { Surgical treatment, } \\
\text { chemotherapy and } \\
\text { radiotherapy/Leczenie } \\
\text { operacyjne, chemio- } \\
\text { i radioterapia }\end{array}$ \\
\hline
\end{tabular}

\begin{tabular}{|c|c|}
\hline $\begin{array}{l}\text { Contact allergens/Alergeny } \\
\text { kontaktowe }\end{array}$ & $\begin{array}{l}\text { Antihistamines, topical } \\
\text { glucocorticosteroids/ } \\
\text { Leki przeciwhistaminowe, } \\
\text { miejscowo } \\
\text { glikokortykosteroidy }\end{array}$ \\
\hline $\begin{array}{l}\text { Drugs, e.g.: NSAIDs, antibiotics, } \\
\text { psychiatric drugs/Leki, m.in.: } \\
\text { NLPZ, antybiotyki, leki } \\
\text { psychiatryczne }\end{array}$ & $\begin{array}{l}\text { Discontinuation of the } \\
\text { drug causing the reaction/ } \\
\text { Odstawienie leku } \\
\text { wywołującego }\end{array}$ \\
\hline $\begin{array}{l}\text { Erysipelothrix rhusopathiae/ } \\
\text { Erysipelothrix rhusopathiae }\end{array}$ & $\begin{array}{l}\text { Antibiotic therapy: } \\
\text { penicillin or erythromycin/ } \\
\text { Antybiotykoterapia: penicylina } \\
\text { lub erytromycyna }\end{array}$ \\
\hline
\end{tabular}

Antibiotic therapy: penicillin or erythromycin/ Antybiotykoterapia: penicylina lub erytromycyna

Antibiotic therapy: penicillin or erythromycin + clindamycin/ Antybiotykoterapia: penicylina

lub erytromycyna + klindamycyna

Treatment/Leczenie

\section{(n)}

(n)


tient reported that the lesions were quite painful, accompanied by a sensation of burning and heaviness. Laboratory tests performed before the admission to the Teaching Department demonstrated leukocytosis (20.2 thousand/ $\mu \mathrm{l}$ ), anaemia (RBC: 4.14 million/ $\mu \mathrm{l}$, Hgb: $11.4 \mathrm{~g} / \mathrm{dl}$ ) and significantly elevated inflammatory parameters (ESR $86 \mathrm{~mm} / \mathrm{h}, \mathrm{CRP} 411 \mathrm{mg} / \mathrm{l})$. The patient's medical history involved chronic myeloid leukaemia (CML) since 2016, treated with Dasatinib in a drug program, and recurrent Quincke's oedema controlled with loratadine at the dose of $10 \mathrm{mg}$. Physical examination on admission revealed a confluent, inflammatory, excessively warm erythema involving the entire skin of the back from the neck to midbuttocks, spreading to lateral surfaces of the abdomen (figs. 1 A, B). Skin lesions were associated with a considerable tenderness. Laboratory tests revealed increased inflammatory parameters (ESR: $85 \mathrm{~mm} / \mathrm{h}$, CRP: $164 \mathrm{mg} / \mathrm{l})$, leukocytosis (17 thousand/ $\mu \mathrm{l})$, and increased LFTs (AST: 57 U/1). Histopathological examination of the obtained specimen revealed scanty infiltrations of T cells (CD3+), neutrophils, histiocytes and single B cells (CD20+) in the dermis around the vessels and skin appendages. Blood was collected for aerobic and anaerobic culture - results were negative. Crystalline penicillin and intravenous clindamycin were used in the treatment, as well as anticoagulant and analgesic treatment, and local cooling ointment, observing a significant improvement in skin lesions (figs. 2 A, B). Considering the observed elevated
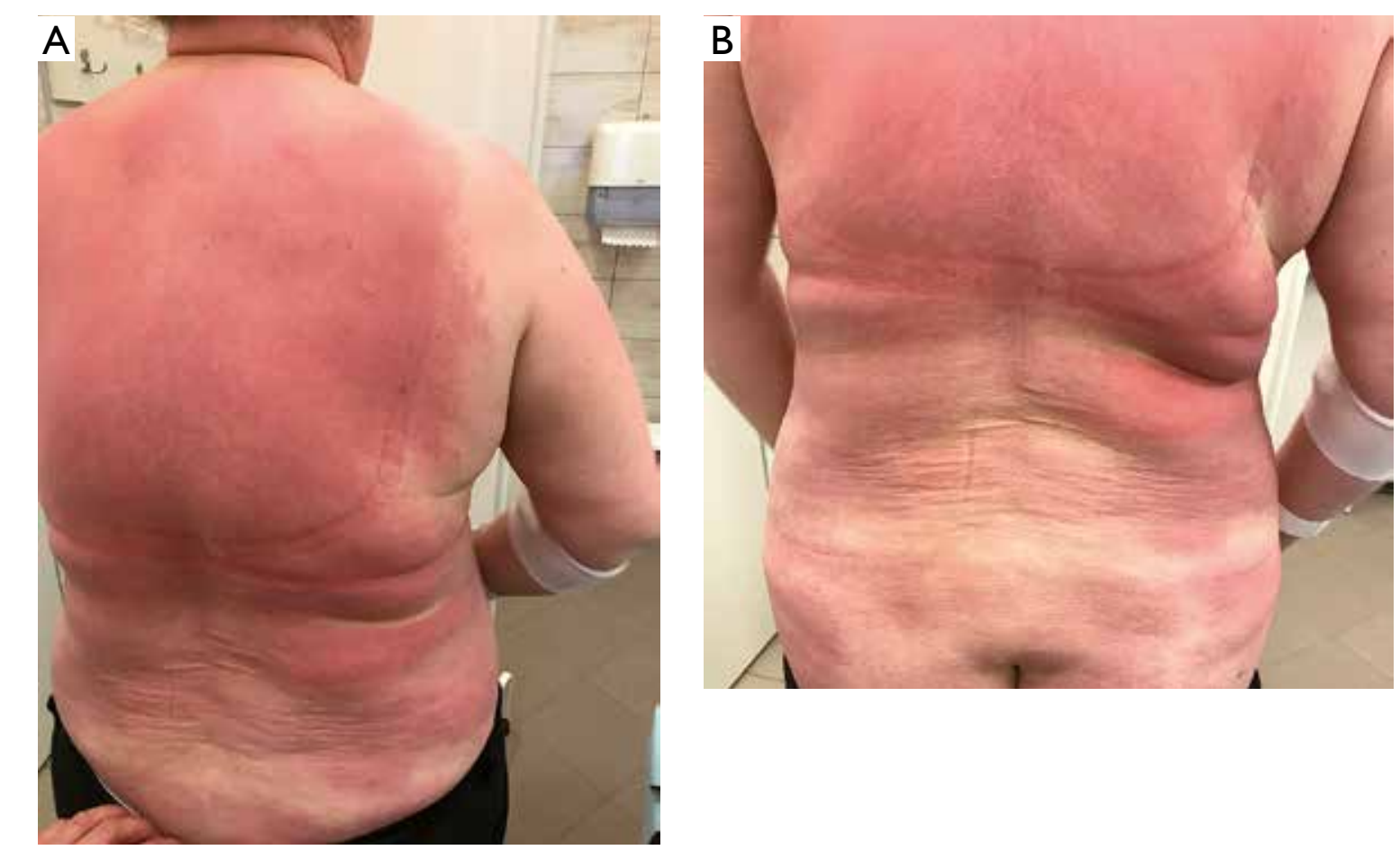

oddziału ratunkowego z powodu pojawienia się zmian skórnych na plecach. W tym czasie była leczona klemastyną, deksametazonem i hydroksyzyną z powodu podejrzenia pokrzywki alergicznej, jednak bez poprawy. Pacjentka podawała, że zmiany były dość bolesne, towarzyszyło im uczucie pieczenia i ciężkości. W badaniach laboratoryjnych wykonanych przed przyjęciem do Kliniki stwierdzono leukocytozę $(20,2$ tys./ $\mu \mathrm{l})$, niedokrwistość (erytrocyty: 4,14 mln/ $\mu$ l, Hgb: 11,4 g/dl) oraz znacznie podwyższone parametry stanu zapalnego (OB $86 \mathrm{~mm} /$ godz., CRP $411 \mathrm{mg} / \mathrm{l}$ ). W wywiadzie pacjentka miała przewlekłą białaczkę szpikową (chronic myeloid leukaemia - CML) od 2016 r. leczoną w programie lekowym dazatynibem oraz nawrotowy obrzęk Quinckego kontrolowany loratadyną w dawce $10 \mathrm{mg}$. W badaniu fizykalnym przy przyjęciu stwierdzono zlewny, zapalny, nadmiernie ucieplony rumień w obrębie całej skóry pleców od szyi aż do połowy pośladków, przechodzący na boczne powierzchnie brzucha (ryc. $1 \mathrm{~A}$, B). Zmianom skórnym towarzyszyła duża tkliwość. W badaniach laboratoryjnych wykazano podwyższone parametry stanu zapalnego (OB: $85 \mathrm{~mm} /$ godz., CRP: $164 \mathrm{mg} / \mathrm{l})$, leukocytozę (17 tys./ $\mu \mathrm{l})$, podwyższenie wartości parametrów wątrobowych (AspAT: $57 \mathrm{U} / \mathrm{l})$. W badaniu histopatologicznym wycinka stwierdzono skąpe nacieki z limfocytów T (CD3+), granulocytów obojętnochłonnych, histiocytów oraz pojedynczych limfocytów B (CD20+) w skórze właściwej wokół naczyń i przydatków skóry. Pobrano

Figure I. At the admission: extensive and confluent erythema covering almost the entire area of the back. "Peau d'orange" sign-thickened skin with dimpled texture

Rycina I. Stan miejscowy przy przyjęciu do Kliniki. Widoczny zlewny, rozległy rumień pokrywający całą powierzchnię pleców. Zmianom towarzyszył twardy obrzęk z drobnymi wgłębieniami, tzw. peau d’orange 
blood pressure, $2.5 \mathrm{mg}$ ramipril was introduced. The patient reported tongue swelling, dexamethasone $8 \mathrm{mg}$ was administered intravenously once, ramipril was changed to amlodipine $5 \mathrm{mg}$ and serum was collected for total-IgE (466 IU/ml). Control laboratory tests indicated reduced values of inflammatory parameters (CRP: $22 \mathrm{mg} / 1$, ESR: $23 \mathrm{~mm} / \mathrm{h}$ ) and leukocytosis (7.78 thousand $/ \mu 1)$. Provocation tests are planned in future.

\section{DISCUSSION}

The characteristic clinical presentation, results of laboratory test and significant improvement achieved with antibiotic therapy support the diagnosis of erysipelas. In the case of the described patient, the differential diagnosis had to take into account also skin changes in the course of leukaemia and carcinomatous erysipelas.

Cutaneous symptoms are not uncommon in patients with leukaemia and there are two types of symptoms [6, 7]. The first type involves nonspecific changes in the form of the so-called leukemid, including pruritus, vasculitis, erythema, erythroderma or erythema nodosum, as well as bullous pemphigoid $[7,8]$. Specific changes - leukaemia cutis and leukemic vasculitis, occur less frequently and are associated with skin infiltration by cancer cells $[7,9]$. Because of the non-specific clinical presentation and great di-
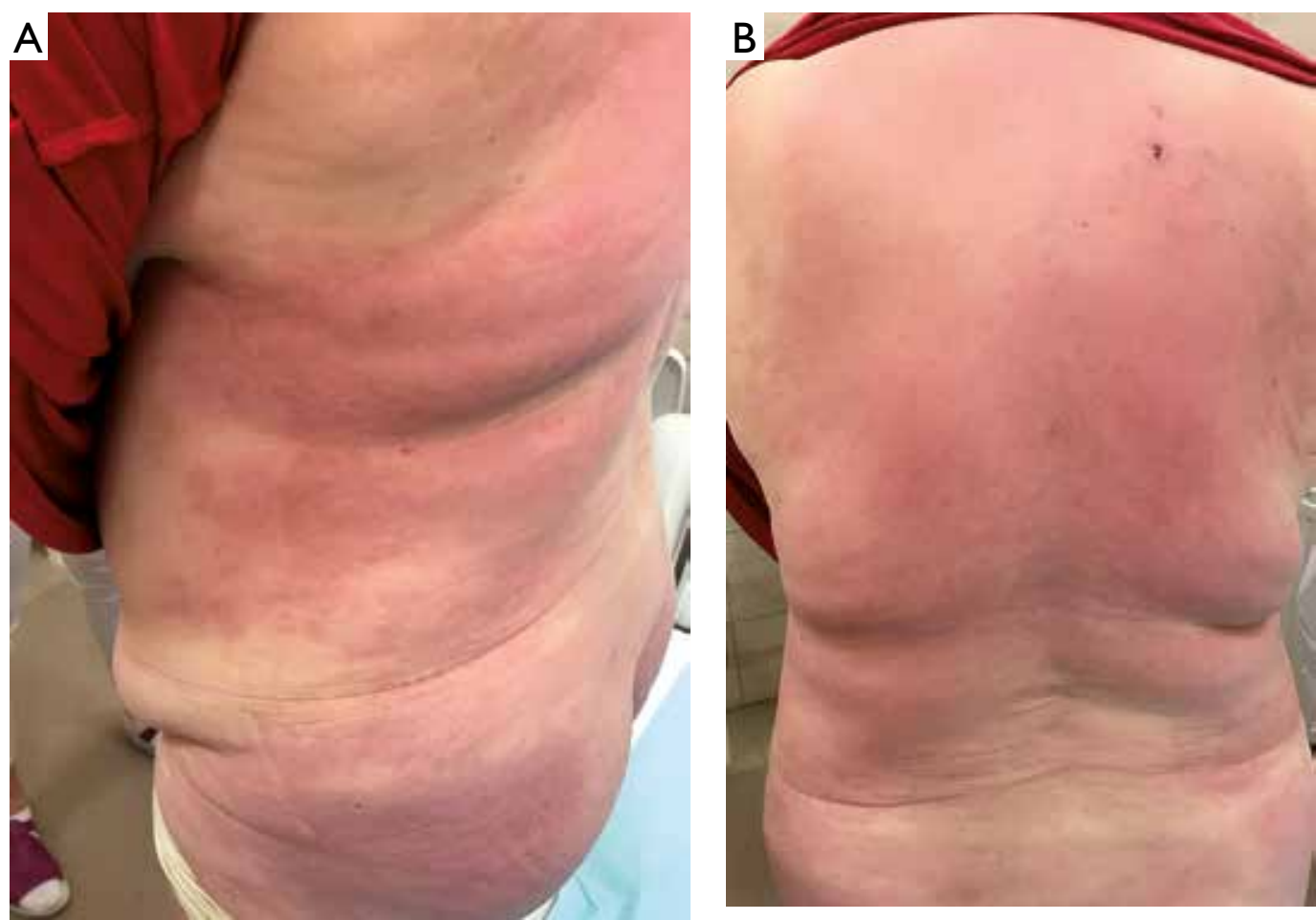

Figure 2. Significant improvement after treatment: reduction of the size and redness of the erythema

Rycina 2. Znaczna poprawa stanu miejscowego - zblednięcie i zmniejszenie zasięgu rumienia 
versity, skin lesions developing in the course of leukaemia may pose a significant diagnostic problem [9]. In the case of CML, skin infiltration by leukemic cells is rare (2-8\% of patients), and non-specific, noncarcinomatous skin lesions are much more common in those patients [10].

Carcinomatous erysipelas is a rare form of metastasis, in which cancer cells spread via superficial lymphatic vessels [11]. Erythematous skin lesions are well demarcated, with a slightly raised edge, and accompanied by tenderness. There are no general symptoms in the course of carcinomatous erysipelas. The most common location of lesions is the chest, followed by upper limbs, the face and neck. In most cases, carcinomatous erysipelas coexists with breast cancer. Cases related to melanoma, thyroid, larynx, lung, ovary, pancreas and stomach cancer have been reported $[12,13]$. It may also occur after chemotherapy and radiotherapy, as well as after surgical procedures with lymph node removal [14]. A biopsy is required for a definitive diagnosis.

\section{CONCLUSIONS}

In the case of the described patient, the atypical location of skin lesions could be caused by the impairment and dysregulation of her immune system, both secondary to leukaemia and the use of an immunosuppressive drug. Less common locations of this infection should be kept in mind in dermatological practice. Early implementation of appropriate treatment allows to achieve therapeutic success and avoid complications. In the discussed patient, it is reasonable to perform provocation tests to diagnose recurrent Quinck's oedema.

\section{CONFLICT OF INTEREST}

The authors declare no conflict of interest. świąd, zapalenie naczyń, rumień, erytrodermię lub rumień guzowaty, a także pemfigoid pęcherzowy [7, 8]. Specyficzne zmiany - leukemia cutis oraz leukemic vasculitis, występują rzadziej i są związane z naciekiem skóry przez komórki nowotworowe [7, 9]. Ze względu na niespecyficzny obraz kliniczny i dużą różnorodność zmiany skórne w przebiegu białaczek mogą stanowić istotny problem diagnostyczny [9]. W przypadku CML naciek skóry przez komórki białaczkowe występuje rzadko (2-8\% chorych), znacznie częściej u pacjentów stwierdza się niespecyficzne, nienowotworowe zmiany skórne [10].

Róża nowotworowa jest rzadką postacią przerzutów, w których komórki nowotworowe rozprzestrzeniają się poprzez powierzchowne naczynia limfatyczne [11]. Rumieniowe zmiany skórne są dobrze odgraniczone, z nieznacznie uniesionym brzegiem, towarzyszy im tkliwość. $W$ przebiegu róży nowotworowej nie występują objawy ogólne. Najczęstsze umiejscowienie zmian to klatka piersiowa, następnie kończyny górne oraz twarz i szyja. W większości przypadków róża nowotworowa współistnieje $\mathrm{z}$ rakiem piersi. Opisywane są także przypadki związane z czerniakiem, rakiem tarczycy, krtani, płuc, jajnika, trzustki i żołądka $[12,13]$. Występuje również po chemio- i radioterapii, a także operacjach $\mathrm{z}$ usunięciem węzłów chłonnych [14]. Do ustalenia ostatecznego rozpoznania konieczna jest biopsja.

\section{WNIOSKI}

W przypadku opisywanej pacjentki niecharakterystyczne umiejscowienie zmian skórnych mogło być spowodowane upośledzeniem i dysregulacją układu odpornościowego po przebytej białaczce, a także stosowaniem leku immunosupresyjnego. W praktyce dermatologicznej należy pamiętać o mniej typowych lokalizacjach tego zakażenia. Wczesne wdrożenie odpowiedniego leczenia pozwala osiągnąć sukces terapeutyczny oraz uniknąć powikłań. U opisanej pacjentki zasadne jest wykonanie prób prowokacyjnych w celu diagnostyki nawrotowego obrzęku Quinckego.

\section{KONFLIKT INTERESÓW}

Autorzy nie zgłaszają konfliktu interesów.

\section{References}

Piśmiennictwo

1. Świątecka J., Purzycka-Bohdan D., Szczerkowska-Dobosz A.: Róża krwotoczna nawrotowa kończyny dolnej - opis przypadku. Forum Med Rodz 2015, 9, 477-480.

2. Michael Y., Shaukat N.M.: Erysipelas. In: StatPearls \{Internet\}. Treasure Island (FL): StatPearls Publishing 2020.

3. Celestin R., Brown J., Kihiczak G.: Erysipelas: a common potentially dangerous infection. Acta Dermatovenerol Alp Pannonica Adriat 2007, 16, 123-127. 
4. Grosshans E.M.: The red face: erysipelas. Clin Dermatol 1993, 11, 307-313.

5. Bonnetblanc J.M., Bedane C.: Erysipelas recognition and management. Am J Clin Dermatol 2003, 4, 157-163.

6. Haidari W., Strowd L.C.: Clinical characterization of leukemia cutis presentation. Cutis 2019, 104, 326-330.

7. Szudy-Szczyrek A., Litak J., Zawitkowska J.: Aleukemiczna białaczka skóry jako manifestacja ostrej białaczki limfoblastycznej. Postęp Nauk Med 2014, 4, 271-274.

8. Badzian A., Ciuruś M., Malinowska A.: Skin lesions in acute myeloid leukaemia - case report. Dermatol Rev 2011, 98, 340344.

9. Rosińska A., Adamski Z.: Zmiany skórne jako objaw prodromalny przewlekłej białaczki szpikowej - opis przypadku. Dermatol Klin 2008, 10, 162-165.

10. Singhal M., Sing S., Kumar R.: Extensive cutaneous manifestations: presenting feature of chronic myelocytic leukemia in second blast crisis. Indian J Dermatol 2010, 55, 265-267.

11. Lever L., Holt P.: Carcinoma erysipeloid. Br J Dermatol 1991, 124, 279-282.

12. Nikolaou V., Stratigos A., Frangia K.: Carcinoma erysipeloides deriving from a primary cutaneous squamous cell carcinoma. Int J Dermatol 2011, 50, 754-765.

13. Cox S.E., Cruz P.D.: A spectrum of inflammatory metastasis to skin via lymphatics: three cases of carcinoma erysipeloides. J Am Acad Dermatol 1994, 30, 304-307.

14. Mackowiak P.A.: Rash in a patient with ovarian cancer. Clin Infect Dis 2012, 54, 538

Received: 16.06 .2020

Accepted: 4.10 .2020

Otrzymano: $16.06 .2020 \mathrm{r}$

Zaakceptowano: $4.10 .2020 \mathrm{r}$.

How to cite this article

Wańczyk-Dręczewska B., Owczarczyk-Saczonek A.B., Placek W.J.: Erysipelas in an atypical location. Dermatol Rev/

Przegl Dermatol 2020, 107, 378-384. DOI: https://doi.org/10.5114/dr.2020.99881. 